\title{
Constitutively enhanced lymphatic pumping in the upper limbs of women who later develop breast cancer-related lymphedema
}

Viviana Cintolesi, BSc, ${ }^{1}$ Anthony WB Stanton, $\mathrm{MB} B C h, \mathrm{PhD},{ }^{1}$ Salena K Bains, MRCS, PhD, ${ }^{2}$ Emma Cousins, BSc, ${ }^{1}$ A Michael Peters, MD, FRCR, FRCPath, FRCP, MSc, ${ }^{3}$ Arnie D Purushotham, MD, FRCS, ${ }^{2}$ J Rodney Levick, DSc, DPhil, BM BCh, MA, ${ }^{1}$ and Peter S Mortimer, MD, FRCP ${ }^{1,4,5}$

${ }^{1}$ Cardiovascular and Cell Sciences Research Institute, St George's, University of London, London, United Kingdom

²Department of Research Oncology, King's College London, Guy's Hospital, London, United Kingdom ${ }^{3}$ Department of Nuclear Medicine, Brighton and Sussex University Hospitals NHS Trust, Eastern Road, Brighton, United Kingdom

${ }^{4}$ Department of Dermatology, St George's University Hospitals NHS Foundation Trust, Blackshaw Road, London, United Kingdom

${ }^{5}$ Skin Unit, The Royal Marsden NHS Foundation Trust, Downs Road, Sutton, Surrey, United Kingdom

Name and address for correspondence:

Professor PS Mortimer

Cardiovascular and Cell Sciences Research Institute

St George's, University of London

Cranmer Terrace

London SW17 ORE

United Kingdom 


\section{Abstract}

Background: It has previously been shown that the lymph drainage rate in both upper limbs is greater in women destined to develop breast cancer-related lymphedema (BCRL) than in those who do not develop BCRL, indicating a constitutive predisposition. We explored constitutive differences further by measuring the maximum lymphatic pump pressure $\left(P_{\text {pump }}\right)$ and the rate of ${ }^{99 \mathrm{~m}} \mathrm{Tc}$-Nanocoll transport generated by the contractile upper limb lymphatics before and after breast cancer surgery in a group of women who were followed for 2 years to determine their eventual BCRL or non-BCRL status. Methods and Results: $P_{\text {pump }}$ and tracer transport rate were measured by lymphatic congestion lymphoscintigraphy in the ipsilateral upper limb in 26 women pre- and post-breast cancer surgery. BCRL occurred in $10 / 26$ (38.5\%) cases. $P_{\text {pump }}$ in the women who later developed BCRL $(40.0 \pm 8.2 \mathrm{mmHg})$ was 1.7-fold higher than in those who did not develop BCRL $(23.1 \pm 10.8 \mathrm{mmHg}, p=0.001)$. Moreover the rate of lymph tracer transport into the forearm was 2.2-fold greater in the women who later developed BCRL $(p=0.052)$. Surgery did not significantly reduce $P_{\text {pump }}$ measured 21 weeks post-surgery but impaired forearm tracer transport in pre-BCRL women by $58 \%(p=0.047)$, though not in those who did not develop BCRL.

Conclusions: Women destined to develop BCRL have higher pumping pressures and lymph transport, indicating harder-working lymphatics prior to cancer treatment. Axillary lymphatic damage from surgery appears to compromise lymph drainage in those women constitutively predisposed to higher lymphatic pressures and lymph transport. 


\section{Introduction}

Breast cancer-related lymphedema (BCRL) remains a common sequel to breast cancer treatment, the risk of which is increased by obesity, axillary lymph node dissection and radiotherapy to the regional lymph nodes. ${ }^{1-4}$ The pathophysiology of BCRL is complex and the widely held assumption of regional lymphatic obstruction to the ipsilateral upper limb following axillary trauma (stopcock hypothesis) is an incomplete explanation. Features of BCRL not readily explained by a simple stopcock (obstructive) hypothesis include sparing of many breast cancer patients despite extensive axillary lymph node surgery; the occurrence of BCRL in patients after only sentinel lymph node biopsy; delayed onset of swelling; and non-uniformity of the swelling along the upper limb. Moreover the contralateral upper limb does not appear to be normal in women with unilateral BCRL; it exhibits lymphatic capillary dilatation in the dermis and greater contralateral hand lymph drainage when there is ipsilateral hand swelling. ${ }^{5,6}$

A striking recent finding was that women who later develop BCRL have higher lymph drainage rates in both upper limbs, in both the muscle ( $22 \%-29 \%$ higher) and subcutis ( $22 \%-50 \%$ higher), before any swelling is evident, compared with women who do not later develop BCRL. ${ }^{7}$ The raised lymph drainage rates were observed at 7 months post-surgery, so they could have been either a systemic effect of the cancer treatment or an inherent, constitutive property. To resolve this point a recent prospective study examined breast cancer patients before the cancer surgery. Quantitative lymphoscintigraphy was performed before surgery and the patients followed for 13 months postsurgery. In the 7 out of 38 patients (18\%) who developed BCRL, the pre-operative lymph removal rate constant $k$ was $16 \%$ higher than in patients who did not later develop BCRL. ${ }^{8}$ These findings, along with those of Stanton et al. and Mellor et al., ${ }^{5-7}$ indicate that there are constitutive, pre-operative, bilateral differences in lymphatic physiology in BCRL-destined patients. 
Lymphatic drainage involves active contractile pumping, both in animal models ${ }^{9-12}$ and human limbs. ${ }^{13}$ To assess lymphatic collector vessel pump function in the upper limbs of women with established BCRL, pump function was quantified as the maximum pressure $\left(P_{\text {pump }}\right)$ generated in the collector lymphatics when lymph flow was blocked by inflating a cuff around the upper arm (lymphatic congestion lymphoscintigraphy $\left.{ }^{14}\right) . P_{\text {pump }}$ was found to be significantly impaired in the lymphedematous upper limb, by $38 \%$ relative to healthy control subjects. Moreover there was a strong negative correlation between $P_{\text {pump }}$ and the magnitude of the swelling, i.e., the weaker the pump, the greater the swelling.

To bring together many of the findings reviewed above, we proposed the following working hypothesis. ${ }^{15}$ In pre-BCRL patients the work of lymphatics is already high due to their raised fluid load. After axillary surgery, lymphatic pump failure may then develop in a manner analogous to cardiac failure following a chronically raised afterload (hypertension). Lymphatic afterload is probably increased chronically by axillary lymphatic damage during surgery and radiotherapy, since nodal excision raises lymph outflow resistance in sheep. ${ }^{16}$ The chronically increased work by the lymphatic muscle fibres leads eventually to reduced lymphangion contractility, as in hypertensive heart failure; animal studies show lymphatic failure at increased distending pressures. ${ }^{10,17,18}$ The resulting decline in lymph drainage rate leads to edema in the drainage territory of the failing lymphatics. The chronic pump failure hypothesis offers a rational explanation for the variable delay in onset of BCRL, since a variable period is likely to be required for overload failure to reach a critical point. Pump failure can also offer a rational explanation for the regionality paradox; ${ }^{15,19}$ if the constitutionally weakest lymphatic collector vessels fail first, swelling will be localised to their drainage territory, i.e., hand, forearm or upper arm.

In light of the constitutive, pre-operative differences in lymph flow in lymphedema-destined breast cancer patients, the question arose as to whether these patients might also have constitutive 
differences in lymphatic pump function prior to pump failure. The present study evaluates this possibility by measuring maximum lymphatic pump pressure $P_{\text {pump, }}$, plus several secondary measures of lymphatic transport rate, in the ipsilateral upper limb of women recently diagnosed with breast cancer. The study was carried out on the ipsilateral upper limb before and after axillary lymph node surgery, and the patients were then followed for 2 years to see who did and did not develop BCRL.

\section{Materials and Methods}

\section{Patients}

Twenty-six women, aged $53 \pm 12$ (SD) years and newly diagnosed with breast cancer, were recruited from the Breast Clinics at St George's Hospital, London; The Royal Marsden Hospital, Sutton, Surrey; and Croydon University Hospital, Croydon, Surrey, UK. The study was approved by the National Research Ethics Service Committee (reference 09/H0701/112) and by the Administration of Radioactive Substances Advisory Committee (ARSAC) (certificate number 295/3230/25986). Procedures were carried out in accordance with the Declaration of Helsinki (2013) of the World Medical Association. All patients gave written informed consent.

Details of the breast cancer and its treatment are summarised in Table 1. Patients underwent mastectomy or wide local excision, and axillary lymph node clearance surgery (ANC) or sentinel lymph node biopsy (SLNB), as recommended by the multidisciplinary team. All patients received adjuvant radiotherapy. Baseline upper limb assessment and lymphatic congestion lymphoscintigraphy (LCL) were performed before axillary surgery (the presurgical visit) and repeated $21 \pm 15$ (SD) weeks after surgery (the postsurgical visit). Diagnostic assessment for BCRL (without $L C L$ ) was performed at $13.0 \pm 2.8$ months and $25.0 \pm 4.7$ months post-surgery, and also shortly after BCRL onset in the BCRL patients. In 6 patients the post-surgical LCL was not performed because the patients were unavailable or declined, but 
these patients were nevertheless followed to see whether or not they developed BCRL. Height was measured pre-surgery and weight was recorded on all visits to calculate body mass index (BMI). The breast cancer patients who later developed BCRL will be referred to as 'pre-BCRL' patients, and the patients who did not develop BCRL as 'non-BCRL' patients. The ipsilateral upper limb of the pre-BCRL patients was the dominant side in $40 \%$ of cases and the non-dominant side in $60 \%$; in the non-BCRL patients the ipsilateral upper limb was the dominant side in $44 \%$ of cases and the non-dominant side in $56 \%$.

\section{Assessment of the upper limb for lymphedema}

The upper limbs were assessed both by clinical criteria and by volume measurement. The clinical features of BCRL are evident at an early, minor stage that is not readily demonstrated by whole-upper limb volume measurement, because these volumes can change with change in body mass after cancer treatment (see Results). For this reason the diagnosis of BCRL was made clinically, rather than on upper limb volumes per se. A Lymphedema Practitioner independently confirmed the diagnosis of BCRL in every patient. Clinical assessment was performed as previously described. ${ }^{20}$ Briefly, BCRL was considered to be present if any of the following were detectable: (i) decreased visibility of subcutaneous veins on the ventral forearm and dorsal hand; (ii) smoothing or fullness of the medial elbow and distal upper arm contours; (iii) increased skin and subcutis thickness if the tissues are pinched between finger and thumb; (iv) pitting edema upon application of thumb pressure for $60 \mathrm{~s}$. In addition, the thickness of the posterior axillary fold (PAF) was assessed by the 'pinch test' ${ }^{21}$ Patients with ipsilateral PAF thickening also had upper limb edema. In addition to the clinical assessment, the volume of each upper limb was measured between the ulnar styloid process (wrist) and anterior axillary fold (proximal upper arm) using an opto-electronic limb volumeter (Perometer 350S, Pero-System Messgeräte GmbH, Wuppertal, Germany). ${ }^{22}$ 


\section{Lymphatic congestion lymphoscintigraphy (LCL)}

LCL was performed as described, ${ }^{14}$ with minor changes (below). To check the efficacy of tissue compression by the upper arm congestion cuff, preliminary experiments were performed in which antecubital venous pressure $\left(P_{\mathrm{v}}\right)$ was compared directly with the applied cuff pressure $\left(P_{\text {cuff }}\right)$ in the upper limb of 6 healthy participants. The participant reclined on a bed with the forearm at heart level. A cannula (Venflon 18G) was inserted into the antecubital vein and connected via fine bore tubing containing heparinised saline to a calibrated pressure transducer (SensoNor dome transducer and BPM832 pressure amplifier; Linton Instrumentation). $P_{\mathrm{v}}$ was displayed on a computer-based data recording system (PowerLab 4/30 and LabChart, AD Instruments; PMS Ltd.). A standard blood pressure cuff around the upper arm was inflated in a series of steps over the range $22-46 \mathrm{mmHg}$. $P_{\mathrm{v}}$ increased in parallel with the increases in $P_{\text {cuff, }}$ albeit with absolute values $2.9-3.1 \mathrm{mmHg}$ less than $P_{\text {cuff. }}$ These results showed that the congesting cuff pressures were transmitted to the deeper tissues with minor attenuation, in accordance with the routine use of congesting cuffs to measure arterial blood pressure.

For the LCL study the patient lay supine on a bed and the brachial artery blood pressure (BP) was measured by auscultation from the contralateral upper limb using a mercury sphygmomanometer and a Riva-Rocci congestion cuff (AC Cossor \& Son Ltd.). For 2 patients with particularly big upper limbs the larger, alternative cuff size was used, and the standard size for all others. The cuff was secured around the ipsilateral upper arm with the tubing at the top and the cuff bladder centered anteriorly. The cuff was wrapped closely and evenly around the limb and the overlap fastened down with adhesive tape. The sphygmomanometer was then reattached to the cuff. The upper limb was supported so that the forearm was horizontal and at heart level. The gamma camera (Argus Epic; MIC Ltd.) (128 x 128 matrix, low-energy general purpose collimator) was positioned above the ipsilateral upper limb for ventral viewing, with the forearm, upper arm, axilla, and adjacent part of the trunk within the field of 
view. Patients acclimatised to their surroundings for $45 \mathrm{~min}$, including $20 \mathrm{~min}$ whilst lying down before the tracer injection and scan. The ambient laboratory temperature was $24.0 \pm 0.6(\mathrm{SD}){ }^{\circ} \mathrm{C}(n=26)$ on the presurgical visit and $23.8 \pm 0.6^{\circ} \mathrm{C}(n=20)$ postsurgery. Skin temperature, recorded from the ipsilateral forearm (YSI 4600 digital thermometer; Henleys Medical Supplies Ltd.), was $29.6 \pm 1.3^{\circ} \mathrm{C}$ presurgery and $29.5 \pm 1.5^{\circ} \mathrm{C}$ postsurgery.

The cuff was inflated to $60 \mathrm{mmHg}$ (or $50 \mathrm{mmHg}$ if the diastolic BP was $<60 \mathrm{mmHg}$ ), using the sphygmomanometer. After 2 min of congestion, $50 \mu \mathrm{L}$ of ${ }^{99 \mathrm{~m} T \mathrm{Tc}-N a n o c o l l}$ (GE Healthcare) of activity $8.4 \pm$ 1.6 $\mathrm{MBq}(n=26)$ was injected intradermally between the $2^{\text {nd }}$ and $3^{\text {rd }}$ metacarpal heads of the ipsilateral hand, using a microneedle of outer diameter $0.2 \mathrm{~mm}$ (Unimed SA). The effective dose was $0.03 \mathrm{mSv}$. The injections were performed consistently and by the same operator throughout, taking on average $52 \pm 13$ $\mathrm{s}(n=26)$ to complete. The injected activity was $8.1 \pm 1.5 \mathrm{MBq}$ and the duration of the injection was $57 \pm$ $16 \mathrm{~s}$ for the pre-BCRL group, and $8.6 \pm 1.6 \mathrm{MBq}$ and $49 \pm 11 \mathrm{~s}$ for the non-BCRL group $(n=10$ and $16, p=$ 0.41 and 0.18 , unpaired $t$-tests). Lymphatic density is higher in the dermis than subcutis, so dermal injections provide rapid access of the tracer to the upper limb collector lymphatics for gamma-camera imaging. ${ }^{23-25}$ Lymphatic vessels are not readily imaged following intramuscular administration of radiotracer in the upper limb. ${ }^{269 \mathrm{~m}} \mathrm{Tc}-$ Nanocoll was used as the lymphatic tracer instead of Technescan HIG (human IgG), used formerly, ${ }^{14}$ because Technescan HIG had been withdrawn from the market by the sole manufacturer. Radiochemical purity of the ${ }^{99 m}$ Tc-Nanocoll was $\geq 95 \%$.

Following injection, dynamic imaging was performed at a frame rate of $2.5 \mathrm{~min}$ for $70 \mathrm{~min}$. The cuff pressure $\left(P_{\text {cuff }}\right)$ was held at $60 \mathrm{mmHg}$ for $10 \mathrm{~min}$, a period long enough to demonstrate trapped tracer unable to pass beyond the lower border of the cuff. $P_{\text {cuff }}$ was then deflated in $10 \mathrm{mmHg}$ steps every $10 \mathrm{~min}$ until $P_{\text {cuff }}=0 \mathrm{mmHg}$. In a further static image acquired after completion of the dynamic sequence while the patient remained in position, outline representations of the forearm, cuff and 
shoulder regions were traced onto the camera face using a ${ }^{57} \mathrm{Co}$ pen marker (High Technology Sources Ltd.); the regions thus delineated were used to create templates for the region of interest analysis of the dynamic images (see below). The syringe activity was measured before and after injection using the gamma camera, to calculate the injected activity. No blood samples were collected.

\section{Measurement of lymphatic function}

Three regions of interest (ROI) were analysed, namely the forearm (ROI1), the subcuff region of the upper arm (ROI2), and the axillary-supraclavicular region (ROI3) (Fig. 1). The counts from each 2.5 min acquisition were plotted against time for each ROI. At high cuff pressures the tracer was transported into the forearm and on towards the lower border of the cuff, but was unable to move more proximally because the lymphatic pump was unable to generate sufficient pressure to overcome the cuff pressure. As cuff pressure was reduced, there came a point at which lymphatic pressure was high enough to force tracer under the cuff and into the axilla.

Primary measure of lymphatic function, $P_{\text {pump }}(\mathrm{mmHg}) P_{\text {pump }}$ was defined as the $P_{\text {cuff }}$ at which radioactivity in ROI3 (axilla) first exceeds the background level (the lymphatic pump pressure). ${ }^{14}$ Secondary indices of lymphatic transport The secondary indices of lymphatic transport, derived using fractional counts (local counts divided by injected activity), were (1) the rate of rise of ${ }^{99 \mathrm{~m} T c-N a n o c o l l}$ activity in ROI1 during the initial 2.5-10.0 min period of trapped lymph $\left(d A / d t_{\mathrm{RO} 11}, \min ^{-1}\right) ;(2)$ the maximum ${ }^{99 \mathrm{~m}} \mathrm{Tc}-\mathrm{Nanocoll}$ count in ROI1; and (3) the rate of rise of ${ }^{99 \mathrm{~m}} \mathrm{Tc}-\mathrm{Nanocoll}$ activity in ROI3 over the virtually linear, 20 min segment of the counts-versus-time plot after $P_{\text {pump }}$ exceeded $P_{\text {cuff }}\left(d A / d t_{\text {ROI3, }}\right.$, $\left.\mathrm{min}^{-1}\right)$. Linear transport occurred at 35-55 $\mathrm{min}$ for the pre-BCRL group and 42.5-62.5 $\mathrm{min}$ for the nonBCRL group. All activities were corrected for physical decay of the radionuclide with standardisation to time of injection. 


\section{Statistical analysis}

Results are presented as the mean \pm standard deviation (SD) in the text and as the mean \pm standard error of the mean (SEM) in the tables and figures. The normality of data sets was tested using the D'Agostino-Pearson Omnibus test. Student's paired or unpaired $t$-test was used to compare differences between groups, or the Mann-Whitney test in the case of non-Gaussian distribution (comparison of $P_{\text {pump }}$ in the pre-BCRL and non-BCRL groups). The foregoing together with linear regression and two-way analysis of variance (ANOVA) were as implemented in GraphPad Prism version 6 (GraphPad Software). Differences were considered significant if $p \approx 0.05$ or less.

\section{Results}

Clinical, surgical and morphometric data

Incidence of BCRL and cancer treatment BCRL was diagnosed clinically in $10 / 26$ women (38.5\%), with onset at $7 \pm 4$ months (0-12 months) postsurgery. BCRL developed in 7/14 (50.0\%) patients undergoing mastectomy, $3 / 12$ (25.0\%) patients undergoing wide local excision, 9/20 (45.0\%) patients undergoing axillary lymph node clearance, and 1/6 (16.7\%) undergoing sentinel lymph node biopsy. The number of lymph nodes removed in the pre-BCRL group, $16.0 \pm 9.3$ per patient, was not significantly different from non-BCRL, $13.3 \pm 10.5$ ( $p=0.52$, unpaired $t$-test). The number of removed nodes that were positive for cancer was again similar in the two groups ( $4.5 \pm 3.5$ pre-BCRL versus $3.3 \pm 4.2$ non-BCRL, $p=0.46$ ).

Upper limb volumes Before surgery, both the ipsilateral and contralateral upper limb volumes for the pre-BCRL group were greater than for the non-BCRL group, by $22.1 \%(p=0.055$, unpaired $t$-test; Table 2$)$ and $21.5 \%$ respectively $(p=0.054)$. Surgery had no statistically significant early (i.e., at mean 21 weeks) effect on upper limb volume in either the pre-BCRL or non-BCRL group (Table $2 ; p=0.31$ and 0.48 for pre-BCRL ipsilateral and contralateral upper limbs respectively; $p=0.80$ and 0.64 for non-BCRL, paired $t$ tests). The above analysis hides a significant difference, however; after surgery, ipsilateral volume was 
significantly greater than contralateral volume in the pre-BCRL patients $(p=0.040)$, due to small, divergent changes; there was a small increase in ipsilateral volume (not itself statistically significant) and a small fall in contralateral volume (not itself statistically significant), resulting in a significant difference between the upper limbs (Fig. 2). Over 2 years ipsilateral upper limb volume tended to increase with time in the pre-BCRL group, as expected, but not in the non-BCRL group or contralateral upper limbs in either group. In some cases the increase in ipsilateral upper limb volume was very small, especially at the time of diagnosis, emphasising the importance of using clinical criteria to diagnose early BCRL. ${ }^{20}$ Body mass index (BMI) Prior to surgery the pre-BCRL group's mean BMI $\left(29.5 \pm 5.0 \mathrm{~kg} / \mathrm{m}^{2}\right)$ was $17 \%$ higher than that of the non-BCRL group $\left(25.2 \pm 3.7 \mathrm{~kg} / \mathrm{m}^{2}\right)(p=0.059)$, in keeping with their $22 \%$ greater upper limb volumes. Higher BMI is a known risk factor for BCRL; ; ${ }^{1,27}$ our data indicate that upper limb volume is also a risk factor. BMI did not change significantly up to 25 months postsurgery $(p=0.94$ for time-points, two-way ANOVA).

\section{Tracer movement along the lymphatic system of the upper limb}

Representative images from a dynamic scan of a pre-BCRL, pre-surgical patient are shown in Figure 1.

The radiotracer entered the hand and forearm lymphatics rapidly, in some cases while the injection was still in progress ( $<1 \mathrm{~min})$. After the injection was complete, the tracer traversed the distance from the hand depot to the distal border of the cuff (mean distance $30.4 \mathrm{~cm}$ ) at a velocity of $7.2 \pm 4.3 \mathrm{~cm} / \mathrm{min}(n=$ 26). Up to 3 (mean 1.6) lymph tracks were imaged in the forearm during pre-surgical LCL and 1-4 (mean 1.7) tracks during the post-surgical LCL. Dermal rerouting of lymph drainage was not evident in any patient, either pre- or postsurgery. Tracer accumulated at the distal border of the congestion cuff until the pressure in the cuff was lowered sufficiently to allow tracer to pass under the cuff (ROI2) and into the axilla (ROI3). 
Comparison of lymphatic function in the pre-BCRL and non-BCRL patients before surgery

$\boldsymbol{P}_{\text {pump }}$ before surgery Maximum lymphatic pump pressure in the pre-BCRL and non-BCRL groups was compared at the pre-surgical time-point in order to test the hypothesis that there is an early, constitutive difference in lymphatic pumping in pre-BCRL women. Individual $P_{\text {pump }}$ values are plotted in Figure 3. $P_{\text {pump }}$ in the pre-BCRL group $(40.0 \pm 8.2 \mathrm{mmHg})$ was on average $73 \%$ higher than $P_{\text {pump }}$ in the non-BCRL group ( $23.1 \pm 10.8 \mathrm{mmHg}, n=10$ and $16 ; p=0.0007$, Mann-Whitney test). A bimodal distribution of $P_{\text {pump }}$ has been reported previously in healthy individuals. ${ }^{14}$ It is interesting to note that when the $P_{\text {pump }}$ values of both pre- and non-BCRL groups are pooled, a bimodal distribution is evident (Fig. 3, right array). This raises the possibility that two human populations, with high and low $P_{\text {pump }}$ respectively, account for the bimodality in the data of Modi et al. ${ }^{14}$

Lymphatic transport dynamics before surgery There were large differences in the lymphatic transport of ${ }^{99 \mathrm{~m}} \mathrm{Tc}-\mathrm{Nanocoll}$ between the two groups before surgery. These are illustrated in Figure 4A, B, which shows the time-courses of activity in each of the three ROls over the duration of the 70 min scan. Several features distinguished the pre-BCRL from the non-BCRL group. (i) The rate of rise of tracer activity in ROI1 during the initial trapped lymph phase $(2.5-10.0 \mathrm{~min}), d A / d t_{\text {ROI1, }}$ was faster in the preBCRL patients that in the non-BCRL patients. (ii) The peak, accumulated activity in ROI1 during the trapped lymph phase was higher in pre-BCRL than non-BCRL patients. (iii) The rate of rise activity in ROI3 after tracer began to be pumped beyond the cuff, $d A / d t_{\mathrm{RO} 33}$, was faster in pre-BCRL than non-BCRL patients. Data analysis (Table 3 ) showed that $d A / d t_{\text {Rol1 }}$ for pre-BCRL patients was approximately double that for non-BCRL patients ( $p=0.052)$ and $d A / d t_{\text {ROI3 }}$ for pre-BCRL patients was 1.55 times higher than for non-BCRL patients $(p<0.0001)$. All four measures of lymphatic function were thus consistent with a more active lymphatic pump in pre-BCRL patients compared with non-BCRL patients.

Comparison of lymphatic function before and soon after surgery 
Pre-BCRL patients, before versus soon after surgery The marginal decline in $P_{\text {pump }}$ from $40.0 \pm 8.2$ $\mathrm{mmHg}$ prior to surgery to $36.7 \pm 10.0 \mathrm{mmHg}$ at 21 weeks after surgery was not statistically significant ( $n$ $=9$ pairs, $p=0.50$, paired $t$-test). By contrast, the indices of lymphatic transport in pre-BCRL patients were all significantly lower at 21 weeks postsurgery (Fig. 4 A versus C, Fig. 5). During the trapped-lymph phase, $d A / d t_{\text {ROI1 }}$ postsurgery fell to $42 \%$ of its presurgery level ( $p=0.047$, comparison of slopes) and the maximum count in ROI 1 fell to $51 \%$ of the presurgery level ( $p=0.025, n=9$, paired $t$-test). When cuff pressure was lower than lymph pressure, $d A / d t_{\text {RO।3 }}$ post-surgery fell to $27 \%$ of the presurgery level $(p<$ 0.0001 , comparison of slopes).

Non-BCRL patients, before versus soon after surgery Surgery had much less effect on the lymphatic system in non-BCRL patients than in pre-BCRL patients. $P_{\text {pump }}$ was well maintained at 21 weeks after surgery in the non-BCRL patients (presurgery $23.1 \pm 10.8 \mathrm{mmHg}$, postsurgery $24.5 \pm 11.3 \mathrm{mmHg} ; n=11$ pairs, $p=0.78$, paired $t$-test). The two lymphatic transport indices for ROI1 were likewise little changed postsurgery (Fig. 4 B versus D, Fig. 5); $d A / d t_{\text {RoI1 }}$ was not reduced ( $21 \%$ increase not significant, $p=0.56$ ) and the maximum count in ROI 1 was not reduced ( $20 \%$ increase not significant, $p=0.32, n=11$ ). $d A / d t_{\text {RO13 }}$ declined postsurgery, by $28 \%(p=0.0008)$, but this was a relatively small change compared with the $73 \%$ fall in $d A / d t_{\mathrm{RO} 13}$ in the pre-BCRL patients (Fig. 5).

Comparison of pre-BCRL versus non-BCRL patients soon after surgery After surgery, $P_{\text {pump }}$ for the preBCRL group $(36.7 \pm 10.0 \mathrm{mmHg}, n=9)$ still exceeded that of the non-BCRLs $(24.5 \pm 11.3 \mathrm{mmHg}, n=11)$ but the difference was smaller than before surgery $(12.1 \mathrm{mmHg} ; p=0.022$, unpaired $t$-test). Because $d A / d t_{\mathrm{ROI1}}$ in the pre-BCRL group had been greatly reduced by surgery, it was no longer higher than in the non-BCRL group $(p=0.45)$. The same was true for peak activity in ROI $(p=0.18)$. In the case of $d A / d t_{\mathrm{ROI3}}$, the decrease caused by surgery in the pre-BCRL group was so large that the pre-BCRL value after surgery was significantly lower than in the non-BCRL group $(p=0.0003)$. 


\section{Discussion}

The primary aim of this study was to test the hypothesis that women destined to develop BCRL after breast cancer treatment have constitutive differences in upper limb lymphatic physiology. The previous evidence underlying the hypothesis was summarised in the Introduction and included raised lymph flows in pre-BCRL women. ${ }^{7,8}$ The present data, obtained before axillary lymph node surgery or radiotherapy, support the hypothesis; the results showed highly significant differences in lymphatic pump pressure and lymph tracer transport between those who later developed BCRL and those who did not. Moreover the data indicate a more active, not weaker lymphatic system in the pre-BCRL women. By contrast, once long-standing lymphedema is present (mean 7.4 years), $P_{\text {pump }}$ is reduced, indicating a weakened lymphatic pump. ${ }^{14}$ The second main finding was that although the breast cancer treatment did not cause a significant, early (21 week) fall in lymphatic pump pressure, it did cause striking reductions in forearm lymph transport rates in the pre-BCRL patients, with relatively little effect in nonBCRL patients. Thus, whereas a marked fall in pump pressure is a later event in lymphedema development, ${ }^{14}$ our new results reveal evidence of impaired lymphatic transport rates within 5 months of treatment.

\section{Upper limb volumes, incidence of BCRL and risk factors}

We applied strict clinical criteria, developed previously, for the diagnosis of BCRL. ${ }^{20}$ The diagnosis of early, mild BCRL based purely on volume measurement can be confounded by other factors, such as weight change, that affect upper limb size. ${ }^{28,29}$ The incidence of BCRL (38.5\%) is within the range reported in recent studies; meta-analysis of nine prospective cohort studies gives an incidence of BCRL diagnosed by more than one method of $28.2 \%$ (mean; range $11.8 \%-53.5 \%$ ). ${ }^{1}$ Nevertheless the question arises as to whether 2 years' follow-up is sufficient; DiSipio et al. ${ }^{1}$ reported that the incidence of BCRL increases up to 2 years after diagnosis or surgery (24 studies), whereas two questionnaire studies 
reported an increase beyond 2 years. ${ }^{30,31}$ Paskett et $a l .{ }^{30}$ reported that whereas the estimated prevalence (repeated episodes or continuous swelling) was $23 \%-29 \%$ for any assessment interval, the incidence of episodic swelling increased beyond 2 years ( $48 \%$ at 2 years, $54 \%$ at 3 years). Norman et al. ${ }^{31}$ reported an increase in cumulative incidence from $30 \%$ at 2 years to $41 \%$ at 5 years. Data from objective and subjective measures of lymphedema rates can show considerable discordance. ${ }^{27}$ In the present study all cases of BCRL developed within 12 months of surgery and were diagnosed according to strict clinical criteria with confirmation by a Lymphedema Practitioner; no cases were diagnosed in the second year.

The study was not designed to identify risk factors for BCRL but nevertheless showed that BCRL incidence was 2.7-fold higher in the patients receiving axillary lymph node clearance than SLNB. Axillary lymph node clearance surgery is a known risk factor for BCRL. ${ }^{27}$ The number of lymph nodes removed and the number positive for cancer were similar in both the pre-BCRL and non-BCRL groups. Higher BMI is an established risk factor for $\mathrm{BCRL},{ }^{1,27}$ and $\mathrm{BMI}$ was $17 \%$ higher in the pre-BCRL than the non-BCRL group; consistent with this was the $22 \%$ greater ipsilateral and contralateral upper limb volumes in the pre-BCRL group, indicating that upper limb volume is a related risk factor. It is currently unknown whether pre-surgical upper limb volume is an independent risk factor for BCRL.

\section{Constitutively raised lymphatic function in the BCRL-destined group}

The results in Figure 3 showed that collector lymphatics distal to the cuff in pre-BCRL patients were able to pump lymph to a higher maximum pressure than those in non-BCRL patients. Moreover the faster $d A / d t_{\text {ROI1 }}$ and higher maximum activity in ROI1 of pre-BCRL patients indicated a more rapid transport of lymph from the hand depot into the collector lymphatics of the forearm; and the faster $d A / d t_{\mathrm{RO} 3}$ indicated a more rapid transport of lymph into the axilla after $P_{\text {pump }}$ exceeded $P_{\text {cuff. }}$ These findings 
combine to support the hypothesis of constitutively enhanced lymphatic function in women destined to develop BCRL.

\section{LaPlace's law and the raised $P_{\text {pump }}$}

What mechanism(s) might underlie the pre-operative difference in $P_{\text {pump }}$ between the two groups? LaPlace's law states that the pressure $P$ generated by tension $T$ in a thin-walled tube of radius $R$ equals $T / R$. This raises the question of whether the lymphatic smooth muscle contractile force $T$ is greater in pre-BCRL than non-BCRL patients, or whether the collector vessel radius $R$ is smaller. Although we have no direct evidence on this point, increased lymphatic smooth muscle activity (force and/or frequency of contraction) seems the more likely explanation, because the raised $d A / d t_{\mathrm{ROI1}}$ and maximum ROI1 activity indicate an increased rate of lymph transport (flow) - a finding broadly in keeping with the raised lymphatic drainage rate constant $k$ in pre-BCRL patients reported previously. ${ }^{8}$

Limited evidence against a smaller vessel radius comes from the observation of wider initial lymphatics in the contralateral forearms of women with BCRL when compared with the forearms of nonBCRL breast cancer patients; ${ }^{5}$ dilated lymphatic collectors imaged in BCRL limbs (median duration 24 months) by magnetic resonance lymphangiography, ${ }^{32}$ and (in early lymphedema) collector vessel ectasia observed in histological sections from secondary lymphedema of the leg. ${ }^{33}$ Studies employing X-ray lymphangiography have demonstrated dilated lymphatic collectors in BCRL and also following axillary dissection but in the absence of upper limb swelling. ${ }^{34-36}$

\section{Possible causes of raised $P_{\text {pump }}$}

Assuming that the high $P_{\text {pump }}$, along with the other indices, indicates enhanced lymphatic contractile force in pre-BCRL patients, what might cause this? A possible factor is the physiological adaptation of lymphatic smooth muscle, either by hypertrophy or raised contractility, to the chronically high fluid load 
(preload) in pre-BCRL patients. A high fluid load is indicated by the raised lymphatic removal rate constant $k$ in pre-BCRL patients. ${ }^{7,8}$ This is supported by the recent report of raised capillary filtration capacity in both forearms of BCRL patients relative to the forearms of matched breast cancer patients without $\mathrm{BCRL},{ }^{37}$ although equivalent data from pre-BCRL patients is lacking. Also, the findings were based on short (3-4 min) congestions and are contrary to results based on the classic, longer congestion method. ${ }^{38}$ Physiological adaptation of lymphatic smooth muscle to a constitutively high resistance axillary node pathway (afterload) is an additional, speculative possibility. In single lymphangions from the rat mesentery, in which input and output pressures were controlled, elevated afterload triggered a time-dependent increase in lymphatic contractility, modulated by change in preload. ${ }^{18,39}$ Genetic factors have also been related to $B C R L$ susceptibility. ${ }^{40-42}$

Hypothesis linking raised $P_{\text {pump }}$ in pre-BCRL and subnormal $P_{\text {pump }}$ in established BCRL; potential key role of lymphatic collector vessel smooth muscle work

Not only is $P_{\text {pump }}$ in established BCRL lower than the $P_{\text {pump }}$ of normal, healthy subjects but also the severity of the swelling correlates negatively with $P_{\text {pump }}$ indicating that partial failure (weakening) of the collector lymphatic pump over the years contributes to the pathogenesis of BCRL. ${ }^{14}$ The new findings in this study raise the question 'why would women with intrinsically stronger lymphatic pumps than others be more prone to pump failure after surgery?' The high transport rates in the pre-BCRL patients (Fig. $4 A)$, along with their high lymph flows ${ }^{7,8}$ offer a rational, albeit speculative explanation, as follows. The stroke work of a contracting lymphangion $=$ volume of lymph ejected $(\Delta V) \times$ active pressure increase $(\Delta P)$, and the lymphangion work rate $=(\Delta V / t) \times \Delta P$, i.e., lymph flow $\times \Delta P$. The high lymph flow in the preBCRL population thus imposes a chronically high work rate on the lymphatic smooth muscle. We propose that this may be close to the maximum chronically sustainable work rate. Surgical removal of lymph nodes raises the outflow resistance to lymph in sheep. ${ }^{16}$ If the same is true in humans (perhaps 
exacerbated by the radiotherapy), then the previous level of lymph flow can only be maintained by a rise in $\Delta P$ (afterload), further increasing the work rate $(\Delta V / t) \times \Delta P$. Over a long period the increased work may cause a partial failure of lymphangion force generation (intrinsic smooth muscle failure) and/or vessel dilatation; the latter reduces the conversion of wall tension into pressure (LaPlace's law) and may impair lymphatic valve competence. The 'lymphatic work' hypothesis has as its analogue the chronic failure of a dilated heart resulting from a high preload and raised afterload (hypertension). The majority subset of women that avoid BCRL may do so partly because their lymphatic system normally operates at a lower preload, leaving them with a greater reserve pump capacity.

Additional pathogenic factors may also come into play after pump failure, for instance degenerative histopathological processes. A recent study described progressive histopathological changes in collector lymphatic vessels harvested from patients affected by lower limb lymphedema after the surgical removal of lymph nodes for gynaecological cancers. ${ }^{33}$ With increasing disease progression and severity the characteristics of the normal collector lymphatics were lost. In early stage lymphedema most lymphatic vessels were normal or showed ectasia, which by LaPlace mechanics will tend to reduce pump pressure, even if contractile force were unimpaired. A minority of vessels had a thickened wall and narrower lumen. Sclerosis was commoner and ectasia less common with increasing severity of lymphedema. Sclerosis of upper limb collector lymphatics would further impair lymphatic pumping and worsen the swelling. Severe sclerosis was observed in superficial lymphatics in the upper limb of a patient with refractory BCRL of 18 years' duration. ${ }^{43}$ Inflammatory triggers for the above might be aggravated by the association between obesity and an abnormal inflammatory response, perhaps involving macrophage migration. ${ }^{44,45}$

Impaired lymphatic transport dynamics in pre-BCRL patients following axillary surgery 
Transport into forearm from hand depot The slight fall in pre-BCRL $P_{\text {pump }}$ at 4.8 months postsurgery was not statistically significant, yet at the same time point the lymphatic transport into the pre-BCRL forearm was roughly halved; $d A / d t_{\text {ROI1 }}$ fell by $58 \%$, maximum ROI1 activity by $48 \%$. The contrast between the large fall in hand-to-forearm transport rate and relatively unchanged $P_{\text {pump }}$ could be explained if the more distal contractile lymphatics (i.e., between hand depot and forearm) are weaker than proximal ones close to the cuff, which were still capable of generating a high $P_{\text {pump. }}$. The data in Figure $4 \mathrm{~A}$ versus $\mathrm{C}$ may thus be an early clue that distal lymphatics are the weakest link in the chain and begin to fail before more proximal lymphatics.

Transport into the axillary-supraclavicular region The fall in $d A / d t_{\mathrm{RO} 33}$ after surgery was much more pronounced in pre-BCRL ( $73 \%$ reduction) than non-BCRL patients ( $28 \%$ reduction), despite the relatively well maintained $P_{\text {pump }}$ in the pre-BCRL group. The interpretation of $d A / d t_{\mathrm{RO} \text { । }}$ after surgery is complicated by the fact that some lymph nodes have been removed from this ROI. The reduced ROI3 transport in both pre-BCRL and non-BCRL groups may be caused partly by increased lymph drainage resistance after axillary surgery; and the greater reduction in the pre-BCRL group may be caused by the slowed delivery of ${ }^{99 \mathrm{~m}} \mathrm{Tc}-\mathrm{Nanocoll}$ by the markedly impaired forearm transport vessels (transport in series). Other possibilities include more extensive axillary lymphatic trauma from the cancer surgery or radiotherapy, ${ }^{4}$ which the study was not designed to explore.

\section{Limitations of present study}

To test further the hypothesis of a constitutively different $P_{\text {pump }}$ in pre-BRL patients, measurements of $P_{\text {pump }}$ and transport dynamics in both upper limbs would have been valuable. This was not feasible in practice because of the demands it would have placed on the patients shortly before their cancer surgery. $P_{\text {pump }}$ data at 2 years, after lymphedema was established, would be useful, to check on the decline in function known to occur over several years. ${ }^{14}$ Many aspects of the proposed working 
hypothesis remain speculative and call for further work. For example, we are not aware of any comparative study of lymphatic smooth muscle structure and function in the distal collectors versus proximal collectors of the human upper limb; and apparently only one study (in sheep) has examined the effect of node removal on the hydraulic resistance to lymph transport out of a limb.

\section{Conclusions}

A disease model for BCRL emerges from the body of evidence presented in this study. Women destined to develop BCRL have constitutively higher lymph loads and higher lymphatic pumping pressures. Breast cancer treatment per se has relatively little effect on maximum lymphatic pressure generation initially but nevertheless impairs lymph transport in those subsequently developing BCRL. Therefore axillary lymphatic obstruction is not the sole explanation for BCRL; surgery appears to compromise lymph drainage in those women constitutively predisposed but much less so in those women with constitutively lower lymphatic pressures and transport. In women destined to develop BCRL the lymphatic contractile work rate is already high and if this is raised further by increased resistance to axillary drainage following cancer treatment and/or further increase in lymph load, the lymphatics are gradually tipped into chronic failure. This is analogous to high preload and high afterload cardiac failure in systemic hypertension. Reduced lymphatic pump activity then leads to overt clinical edema. The identification of women belonging to an 'at-risk' group, with higher lymphatic preloads prior to cancer treatment, would provide an opportunity for pharmacological intervention aimed at lowering preload; this could in theory prevent BCRL if introduced early enough.

\section{Authors' Note}

Follow-up is now at least 3 years since cancer surgery for all patients, and no further cases of BCRL have developed. 


\section{Acknowledgments}

We acknowledge the support of Cancer Research UK who funded this study (grant number C19621/A11009). We thank the patients. We also thank the Breast Nurses, Research Nurses and Lymphedema Practitioners (St George's, The Royal Marsden, and Croydon University Hospitals) for their help with recruitment and for helping the patients with lymphedema; Mr Anup Sharma and Mr Dibyesh Banerjee (Breast Unit, St George's Hospital), Ms Nicola Roche (Breast Unit, The Royal Marsden Hospital) and Miss Caroline Pogson (Breast Unit, Croydon University Hospital) for help with recruitment; Dr Susan Heenan (Radiology, St George's Hospital), Clinical Radiology Expert; Andy Irwin (Physics, St George's Hospital), Medical Physics Expert; Jim Ballinger (Nuclear Medicine, Guy's Hospital) for advice on radiopharmaceuticals; Vernie Ramalingham (Guy's Hospital) for help with the surveillance of patients; and Mick Rogers (MIC Ltd) for gamma camera technical support.

\section{Author Disclosure Statement}

No competing financial interests exist.

\section{References}

1. DiSipio T, Rye S, Newman B, Hayes S. Incidence of unilateral arm lymphoedema after breast cancer: a systematic review and meta-analysis. Lancet Oncol 2013;14:500-515.

2. Mortimer P. Arm lymphoedema after breast cancer. Lancet Oncol 2013;14:442-423.

3. Basta MN, Fischer JP, Kanchwala SK, Silvestre J, Wu LC, Serletti JM, Tchou JC, Kovach SJ, Fosnot J. A propensity-matched analysis of the influence of breast reconstruction on subsequent development of lymphedema. Plast Reconstr Surg 2015;136:134e-143e. 
4. Whelan TJ, Olivotto IA, Parulekar WR, Ackerman I, Chua BH, Nabid A, Vallis KA, White JR, Rousseau P, Fortin A, Pierce LJ, Manchul L, Chafe S, Nolan MC, Craighead P, Bowen J, McCready DR, Pritchard KI, Gelmon K, Murray Y, Chapman JA, Chen BE, Levine MN; MA.20 Study Investigators. Regional nodal irradiation in early-stage breast cancer. N Engl J Med 2015;373:307-316.

5. Mellor RH, Stanton AWB, Azarbod P, Sherman MD, Levick JR, Mortimer PS. Enhanced cutaneous lymphatic network in the forearms of women with postmastectomy oedema. J Vasc Res 2000;37:501-512.

6. Stanton AWB, Modi S, Mellor RH, Peters AM, Svensson WE, Levick JR, Mortimer PS. A quantitative lymphoscintigraphic evaluation of lymphatic function in the swollen hands of women with lymphoedema following breast cancer treatment. Clin Sci 2006;110:553-561.

7. Stanton AWB, Modi S, Bennett Britton TM, Purushotham AD, Peters AM, Levick JR, Mortimer PS. Lymphatic drainage in the muscle and subcutis of the arm after breast cancer treatment. Breast Cancer Res Treat 2009;117:549-557.

8. Bains SK, Stanton AWB, Cintolesi V, Ballinger J, Allen S, Zammit C, Levick JR, Mortimer PS, Peters AM, Purushotham AD. A constitutional predisposition to breast cancer-related lymphoedema and effect of axillary lymph node surgery on forearm muscle lymph flow. The Breast 2015;24:68-74.

9. McHale NG, Meharg MK. Co-ordination of pumping in isolated bovine lymphatic vessels. J Physiol 1992;450:503-512.

10. Li B, Silver I, Szalai JP, Johnston MG. Pressure-volume relationships in sheep mesenteric lymphatic vessels in situ: Response to hypovolemia. Microvasc Res 1998;56:127-138.

11. McCloskey KD, Hollywood MA, Thornbury KD, Ward SM, McHale NG. Kit-like immunopositive cells in sheep mesenteric lymphatic vessels. Cell Tissue Res 2002;310:77-84.

12. von der Weid PY, Lee S, Imtiaz MS, Zawieja DC, Davis MJ. Electrophysiological properties of rat mesenteric lymphatic vessels and their regulation by stretch. Lymphat Res Biol 2014;12:66-75. 
13. Olszewski WL, Engeset A. Intrinsic contractility of prenodal lymph vessels and lymph flow in human leg. Am J Physiol 1980;239:H775-783.

14. Modi S, Stanton, AWB, Svensson WE, Peters AM, Mortimer PS, Levick JR. Human lymphatic pumping measured in healthy and lymphoedematous arms by lymphatic congestion lymphoscintigraphy. J Physiol 2007;583.1:271-285.

15. Stanton AWB, Modi S, Mellor RH, Levick JR, Mortimer PS. Recent advances in breast cancer-related lymphedema of the arm: lymphatic pump failure and predisposing factors. Lymphat Res Biol 2009;7:29-45.

16. Kim C, Li B, Papaiconomou C, Zakharov A, Johnston M. Functional impact of lymphangiogenesis on fluid transport after lymph node excision. Lymphology 2003;36:111-119.

17. Levick JR, McHale N. The Physiology of Lymph Production and Propulsion. In: Browse N, Burnand KG, Mortimer PS, authors. Diseases of the Lymphatics. London: Arnold; 2003: 44-64.

18. Davis MJ, Scallan JP, Wolpers JH, Muthuchamy M, Gashev AA, Zawieja DC. Intrinsic increase in lymphangion muscle contractility in response to elevated afterload. Am J Physiol Heart Circ Physiol 2012;303:H795-808.

19. Modi S, Stanton AWB, Mellor RH, Peters AM, Levick JR, Mortimer PS. Regional distribution of epifascial swelling and epifascial lymph drainage rate constants in breast cancer-related lymphedema. Lymphat Res Biol 2005;3:3-14.

20. Stanton A, Modi S, Mellor R, Levick R, Mortimer P. Diagnosing cancer-related lymphoedema in the arm. J Lymphoedema 2006;1:12-15.

21. Roberts CC, Levick JR, Stanton AWB, Mortimer PS. Assessment of truncal edema following breast cancer treatment using modified Harpenden skinfold calipers. Lymphology 1995;28:78-88.

22. Stanton AWB, Northfield JW, Holroyd B, Mortimer PS, Levick JR. Validation of an optoelectronic volumeter $\left(\right.$ Perometer $\left.^{\circledR}\right)$. Lymphology 1997;30:77-97. 
23. Stanton AWB, Patel HS, Levick JR, Mortimer PS. Increased dermal lymphatic density in the human leg compared with the forearm. Microvasc Res 1999;57:320-328.

24. O'Mahony S, Rose SL, Chilvers AJ, Ballinger JR, Solanki CK, Barber RW, Mortimer PS, Purushotham $A D$, Peters AM. Finding an optimal method for imaging vessels of the upper limb. Eur J Nucl Med Mol Imaging 2004;31:555-563.

25. Mellor RH, Hubert CE, Stanton AWB, Tate N, Akhras V, Smith A, Burnand KG, Jeffery S, Mäkinen T, Levick JR, Mortimer PS. Lymphatic dysfunction, not aplasia, underlies Milroy disease. Microcirculation 2010;17:281-296.

26. Stanton AWB, Mellor RH, Cook GJ, Svensson WE, Peters AM, Levick JR, Mortimer PS. Impairment of lymph drainage in subfascial compartment of forearm in breast cancer-related lymphedema. Lymphat Res Biol 2003;1:121-132.

27. McLaughlin SA, Wright MJ, Morris KT, Giron GL, Sampson MR, Brockway JP, Hurley KE, Riedel ER, Van Zee K.J. Prevalence of lymphedema in women with breast cancer 5 years after sentinel lymph node biopsy or axillary dissection: objective measurements. J Clin Oncol 2008;26:5213-5219.

28. Miller CL, Specht MC, Horick N, Skolny MN, Jammallo LS, O'Toole J, Taghian, AG. A novel, validated method to quantify breast cancer-related lymphedema (BCRL) following bilateral breast surgery. Lymphology 2013;46:64-74.

29. Vagenas D, DiSipio T, Battistutta D, Demark-Wahnefried W, Rye S, Bashford J, Pyke C, Saunders C, Hayes SC. Weight and weight change following breast cancer: evidence from a prospective, population-based, breast cancer cohort study. BMC Cancer 2015;15:28-36.

30. Paskett ED, Naughton MJ, McCoy TP, Case LD, Abbott JM. The epidemiology of arm and hand swelling in premenopausal breast cancer survivors. Cancer Epidemiol Biomarkers Prev 2007;16:775782. 
31. Norman SA, Localio AR, Potashnik SL, Simoes Torpey HA, Kallan MJ, Weber AL, Miller LT, Demichele A, Solin L. Lymphedema in breast cancer survivors: incidence, degree, time course, treatment, and symptoms. J Clin Oncol 2009;27:390-397.

32. Liu N-F, Wang B-S. Functional lymphatic collectors in breast cancer-related lymphedema arm. Lymphat Res Biol 2014;12:232-237.

33. Mihara M, Hara H, Hayashi Y, Narushima M, Yamamoto T, Todokoro T, lida T, Sawamoto N, Araki J, Kikuchi K, Murai N, Okitsu T, Kisu I, Koshima I. Pathological steps of cancer-related lymphedema: Histological changes in the collecting lymphatic vessels after lymphadenectomy. PLoS ONE 2012;7:e41126,1-10.

34. Abe R. A study on the pathogenesis of postmastectomy lymphedema. Tohoku J Exp Med 1976;118:163-171.

35. Clodius L. Secondary Arm Lymphedema. In: Clodius L, ed. Lymphedema. Stuttgart: Georg Thieme; 1977: 147-174.

36. Mortimer PS. Lymphedema of the Upper Limb. In: Browse N, Burnand KG, Mortimer PS, authors. Diseases of the Lymphatics. London: Arnold; 2003: 231-242.

37. Jensen MR, Simonsen L, Karlsmark T, Lanng C, Bülow J. Higher vascular endothelial growth factor-C concentration in plasma is associated with increased forearm capillary filtration capacity in breast cancer-related lymphedema. Physiol Rep 2015;3:e12403,1-11.

38. Stanton AWB, Holroyd B, Mortimer PS, Levick JR. Comparison of microvascular filtration in human arms with and without postmastectomy oedema. Exp Physiol 1999;84:405-419.

39. Scallan JP, Wolpers JH, Muthuchamy M, Zawieja DC, Gashev AA, Davis MJ. Independent and interactive effects of preload and afterload on the pump function of the isolated lymphangion. Am J Physiol Heart Circ Physiol 2012;303:H809-824. 
40. Finegold DN, Schacht V, Kimak MA, Lawrence EC, Foeldi E, Karlsson JM, Baty CJ, Ferrell RE. HGF and MET mutations in primary and secondary lymphedema. Lymphat Res Biol 2008;6:65-68.

41. Newman B, Lose F, Kedda MA, Francois M, Ferguson K, Janda M, Yates P, Spurdle AB, Hayes SC. Possible genetic predisposition to lymphedema after breast cancer. Lymphat Res Biol 2012;10:2-13.

42. Leung G, Baggott C, West C, Elboim C, Paul SM, Cooper BA, Abrams G, Dhruva A, Schmidt BL, Kober K, Merriman JD, Leutwyler H, Neuhaus J, Langford D, Smoot BJ, Aouizerat BE, Miaskowski C. Cytokine candidate genes predict the development of secondary lymphedema following breast cancer surgery. Lymphat Res Biol 2014;12:10-22.

43. Yamamoto T, Yamamoto N, Hayashi A, Koshima I. Supermicrosurgical deep lymphatic vessel-tovenous anastomosis for a breast cancer-related arm lymphedema with severe sclerosis of superficial lymphatic vessels. Microsurgery 17 Jan 2015;doi:10.1002/micr.22382 (epub).

44. Mehrara BJ, Greene AK. Lymphedema and obesity: Is there a link? Plast Reconstr Surg 2014;134:154e-160e.

45. Ghanta S, Cuzzone DA, Torrisi JS, Albano NJ, Joseph WJ, Savetsky IL, Gardenier JC, Chang D, Zampell JC, Mehrara BJ. Regulation of inflammation and fibrosis by macrophages in lymphedema. Am J Physiol Heart Circ Physiol 2015;308:H1065-1077. 
Table 1. Surgical and pathological data for the breast cancer patients.

\begin{tabular}{|c|c|c|c|c|c|c|c|}
\hline Patient Age & Breast & Axillary & No. of $L N$ & \multicolumn{4}{|c|}{ Tumor histology } \\
\hline$(y r)$ & surgery & surgery & removed (t) & Grade & Type & Size $(\mathrm{mm})$ & $E R$ \\
\hline
\end{tabular}

Pre-BCRL group

$\begin{array}{lllllllll}004 & 69 & \text { WLE } & \text { SLNB } & 4(0) & 3 & \text { IDC } & 13 & + \\ 015 & 42 & \text { WLE } & \text { ANC } & 22(4) & 3 & \text { IDC } & 45 & + \\ 019 & 51 & M & \text { ANC } & 28(10) & 2 & \text { IDC, DCIS } & 43 & + \\ 021^{a} & 74 & M & \text { ANC } & 14(7) & 2 & \text { IDC, DCIS } & 160 & + \\ 022 & 72 & M & \text { ANC } & 17(7) & 3 & \text { IDC, DCIS* } 43 & + \\ 023^{a} & 50 & M & \text { ANC } & 4(3) & 3 & \text { IDC, DCIS } 35 & + \\ 028 & 51 & \text { WLE } & \text { ANC } & 32(8) & 2 & \text { IDC, DCIS } 33 & + \\ 030 & 49 & M & \text { ANC } & 10(5) & 2 & \text { IDC, DCIS* } 70 & + \\ 031 & 38 & M & \text { ANC } & 12(0) & 2 & \text { IDC, DCIS* } 50 & + \\ 039^{a} & 52 & M & \text { ANC } & 17(1) & 3 & \text { IDC } & \text { NR } & \text { NR }\end{array}$

Non-BCRL group

$\begin{array}{lllllllll}003 & 37 & M & \text { ANC } & 15(13) & 2,3 & \text { IDC } & \text { NR } & + \\ 007^{a} & 64 & M & \text { ANC } & 33(12) & 3 & \text { IDC } & 75 & + \\ 010 & 62 & M & \text { ANC } & 9(4) & 2 & \text { IDC } & 35 & + \\ 017^{a} & 50 & \text { M } & \text { ANC } & 16(5) & 2 & \text { IDC } & 20 & + \\ 018 & 43 & \text { WLE } & \text { SLNB } & 5(0) & 2 & \text { IDC, DCIS } & 35 & + \\ 020 & 47 & \text { WLE } & \text { SLNB } & 1(0) & 1 & \text { IDC } & \text { NR } & \text { NR } \\ 024 & 47 & \text { WLE } & \text { ANC } & 2(0) & 1 & \text { ICC } & 11 & +\end{array}$




\begin{tabular}{lllllllll}
025 & 67 & WLE & SNLB & $1(0)$ & 2 & ILC & 11,15 & + \\
027 & 75 & WLE & ANC & $18(5)$ & 2 & IDC, DCIS & 43 & + \\
029 & 35 & M & ANC & $17(3)$ & 2 & IDC & 88 & + \\
032 & 52 & WLE & ANC & $31(3)$ & 3 & IDC & 22 & + \\
034 & 62 & WLE & SLNB & $3(0)$ & 2 & IDC, ILC & 14 & + \\
035 & 40 & WLE & SLNB & $1(0)$ & 1 & IDC, DCIS & 35 & + \\
036 & 47 & M & ANC & $19(1)$ & 3 & IDC, DCIS & 30 & + \\
037 & 42 & WLE & ANC & $20(1)$ & 3 & IDC & 56 & + \\
038 & 49 & M & ANC & $22(6)$ & 3 & IDC & 45 & + \\
\hline
\end{tabular}

Pre-BCRL group: the patients who later developed breast cancer-related lymphedema; non-BCRL group: the patients who did not develop BCRL.

ANC, axillary lymph node clearance surgery; DCIS, ductal carcinoma in situ (*high-grade); ER, oestrogen receptor status (positive [+], negative [-]); ICC, invasive cribriform carcinoma; IDC, invasive ductal carcinoma; ILC, invasive lobular carcinoma; LN, lymph node, with the number positive for cancer in brackets; M, mastectomy; NR, not recorded; SLNB, sentinel lymph node biopsy; WLE, wide local excision. All patients received adjuvant radiotherapy.

${ }^{\text {a Died. }}$ 
Table 2. Ipsilateral and contralateral upper limb volumes in the pre- pre-BCRL patients and the non-BCRL patients, before and after axillary surgery.

Presurgical upper limb volumes $(m L) \quad$ Postsurgical upper limb volumes $(m L)$

Pre-BCRL (10) Non-BCRL (16) $p^{*} \quad$ Pre-BCRL (10) Non-BCRL (11) $p^{*}$

$\begin{array}{llllll}\text { Ipsilateral } \quad 2312 \pm 205 & 1894 \pm 103 & 0.055 & 2369 \pm 226 & 2007 \pm 142 & 0.18\end{array}$

$\begin{array}{lllllll}\text { Contralateral } & 2321 \pm 192 & 1910 \pm 107 & 0.054 & 2227 \pm 202 & 2049 \pm 150 & 0.48\end{array}$

$\begin{array}{lllll}p^{* *} & 0.88 & 0.59 & 0.040 & 0.34\end{array}$

Number of patients in each group shown in brackets; values are means \pm SEM. In both groups, neither the ipsilateral nor the contralateral limb changed significantly in volume by 21 weeks postsurgery. $p^{*}$, comparison of the pre-BCRL and non-BCRL groups (unpaired $t$-test). $p^{* *}$, comparison of the ipsilateral and contralateral upper limbs (paired $t$-test). BCRL, breast cancer-related lymphedema. 
Table 3. Summary of measurements of lymphatic function obtained by lymphatic congestion lymphoscintigraphy in the pre-BCRL and the non-BCRL patients, before and after axillary surgery.

\section{Presurgical measurements Postsurgical measurements}

Pre-BCRL (10) Non-BCRL (16) $p \quad$ Pre-BCRL (9) Non-BCRL (11) $p$

$\begin{array}{lllllll}P_{\text {pump }}(\mathrm{mmHg}) & 40.0 \pm 2.6 & 23.1 \pm 2.7 & 0.0007 * & 36.7 \pm 3.3 & 24.5 \pm 3.4 & 0.022 \\ d A / d t_{\text {ROI1 }}\left(\mathrm{min}^{-1}\right) 2.32 \pm 0.30 & 1.07 \pm 0.35 & 0.052 & 0.98 \pm 0.37 & 1.30 \pm 0.10 & 0.45 \\ & & & & & \\ \text { Peak count } & & & & & \\ & 48.6 \pm 8.11 & 33.7 \pm 3.73 & 0.072 & 25.2 \pm 8.62 & 40.2 \pm 7.09 & 0.18 \\ d A / d t_{\text {ROI3 }}\left(\mathrm{min}^{-1}\right) 0.62 \pm 0.02 & 0.40 \pm 0.02 & <0.0001 & 0.17 \pm 0.01 & 0.29 \pm 0.02 & 0.0003\end{array}$

Number of patients in each group shown in brackets; values are means \pm SEM.

$P_{\text {pump }}$, lymphatic pump pressure; ROI, region of interest; $d A / d t_{\text {ROI1 }}$, rate of rise of fractional count in ROI1 $\left(\times 10^{3}\right)$ determined by linear regression analysis of mean fractional counts over 2.5-10.0 min (pre-BCRL and non-BCRL, $\pm \mathrm{SE}) ; d A / d t_{\mathrm{RO} 33}$, rate of rise of fractional count in $\mathrm{ROI3}\left(\times 10^{3}\right)$ by linear regression analysis of mean fractional counts over 35-55 min (pre-BCRL) or 42.5-62.5 min (non-BCRL) ( $\pm \mathrm{SE}$ ); Peak count $\mathrm{ROI1}_{\text {, }}$ maximum fractional count in ROI1 $\left(\times 10^{3}\right) . p$, comparisons of the pre-BCRL group with the non-BCRL group, before or after surgery (*Mann-Whitney test; comparison of regression slopes for $d A / d t$; unpaired t-test for the other comparisons). See text and Figure 5 for presurgery versus postsurgery statistical comparisons. BCRL, breast cancer-related lymphedema. 

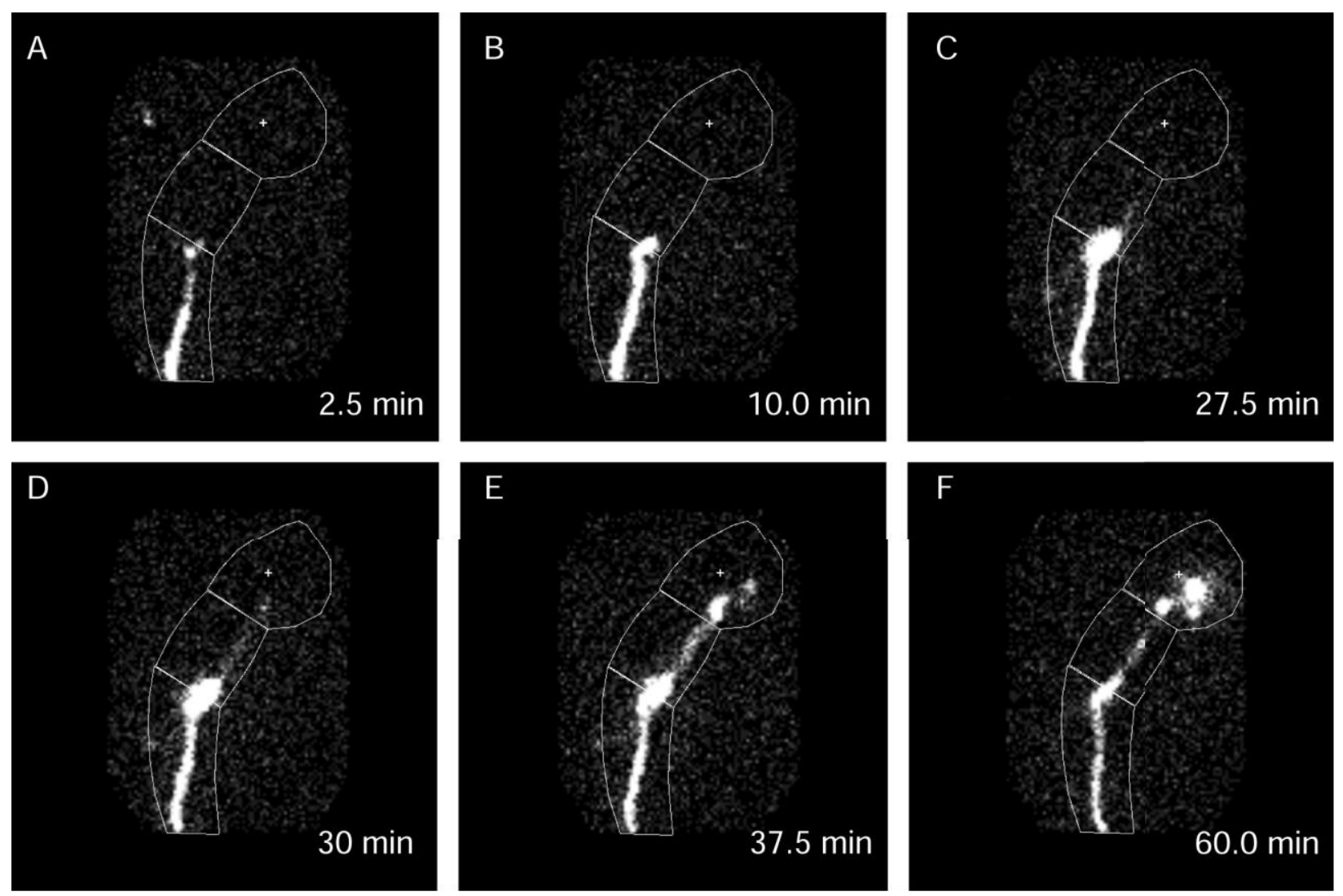

Figure 1. Lymphatic congestion lymphoscintigraphy performed before axillary surgery on the ipsilateral upper limb of a patient who later developed breast cancer-related lymphedema. Three regions of interest (ROI1 [the lowermost ROI], forearm; ROI2, subcuff; ROI3, axilla) are superimposed and the number of minutes elapsed since the injection are shown. (A) $2.5 \mathrm{~min}, P_{\text {cuff }}=60 \mathrm{mmHg}$. The lymphatic tracer has traversed the forearm and reached the distal border of the cuff. (B) $10 \mathrm{~min}, P_{\text {cuff }}=60 \mathrm{mmHg}$. Activity is unable to pass under the cuff. (C) $27.5 \mathrm{~min}, P_{\text {pump }}=40 \mathrm{mmHg}$. Activity has started to pass under the cuff. (D) $30 \mathrm{~min}, P_{\text {cuff }}=40 \mathrm{mmHg}$. Activity has just reached the axilla. $P_{\text {pump }}$ (the cuff pressure at which the intra-lymphatic pressure overcame the surrounding occluding pressure, allowing tracer to pass into ROI3) $=40 \mathrm{mmHg}$. (E) $37.5 \mathrm{~min}, P_{\text {cuff }}=30 \mathrm{mmHg}$. Lymph nodes are imaged in the axilla. (F) 60 $\min , P_{\text {cuff }}=0 \mathrm{mmHg}$. There is prominent nodal activity with tracer persisting in the lymphatics. Images from patient 028. 

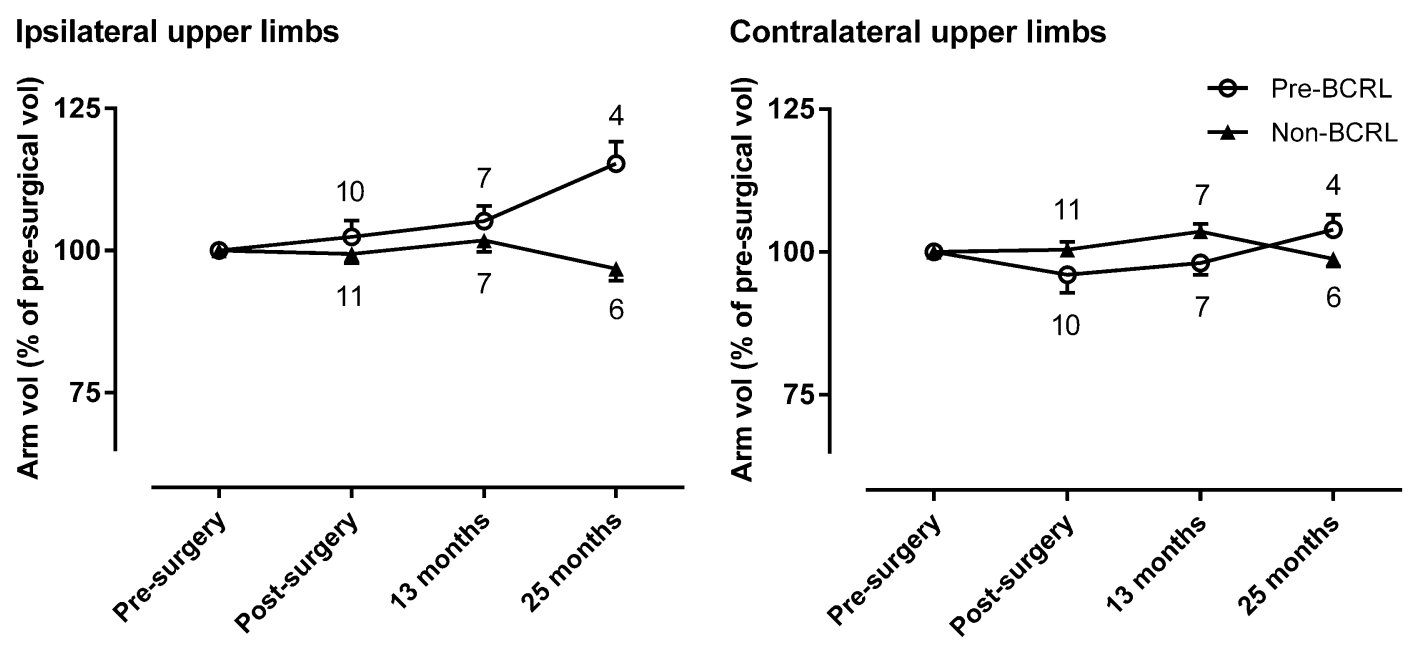

Figure 2. Changes in ipsilateral and contralateral upper limb volume following axillary surgery for the pre-BCRL and non-BCRL patients relative to their presurgical volumes (= $100 \%)$. Means $\pm \mathrm{SEM}$, with the number of patients shown above each point. The postsurgical measurement was at 21 weeks. BCRL, breast cancer-related lymphedema. 


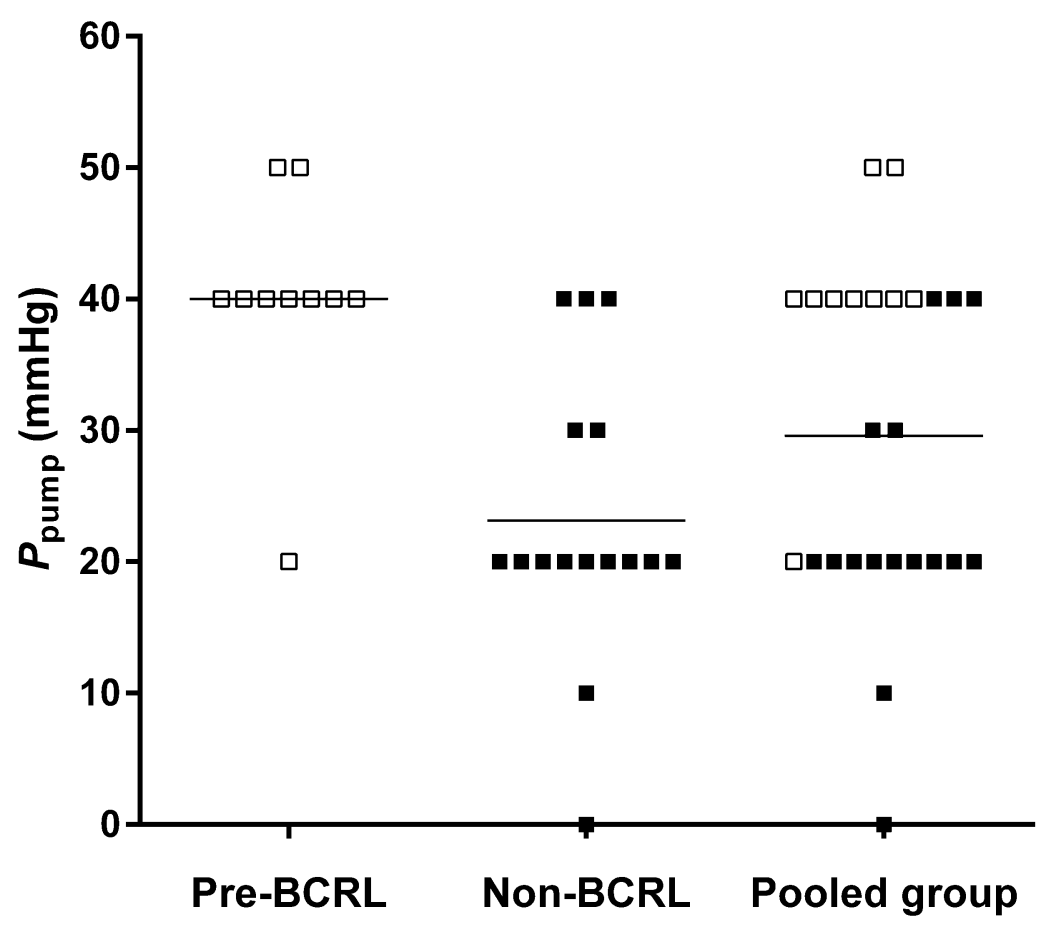

Figure 3. Lymphatic pump pressures $\left(P_{\text {pump }}\right)$ in collector lymphatics of the ipsilateral upper limb in breast cancer patients measured before axillary surgery. The 10 pre-BCRL and 16 non-BCRL patients are shown separately (left and center arrays). $P_{\text {pump }}$ for the pooled group of the 26 patients (right array) shows a bimodal distribution. The horizontal lines indicate the means (40.0, 23.1 and $29.6 \mathrm{mmHg}$, respectively). $P_{\text {pump }}$ was highly significantly greater in the pre-BCRL patients than the non-BCRL patients $(p=0.0007, \mathrm{n}$ $=10$ and 16, Mann-Whitney test). 
Pre-surgery

A Pre-BCRL patients

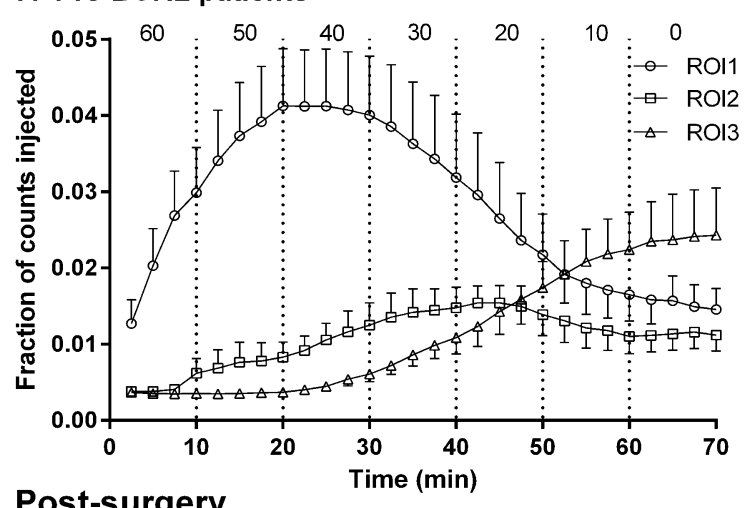

B Non-BCRL patients

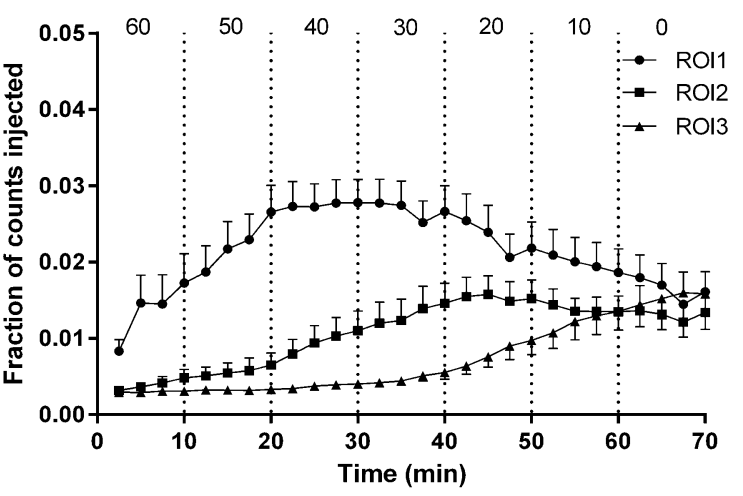

Post-surgery

C Pre-BCRL patients

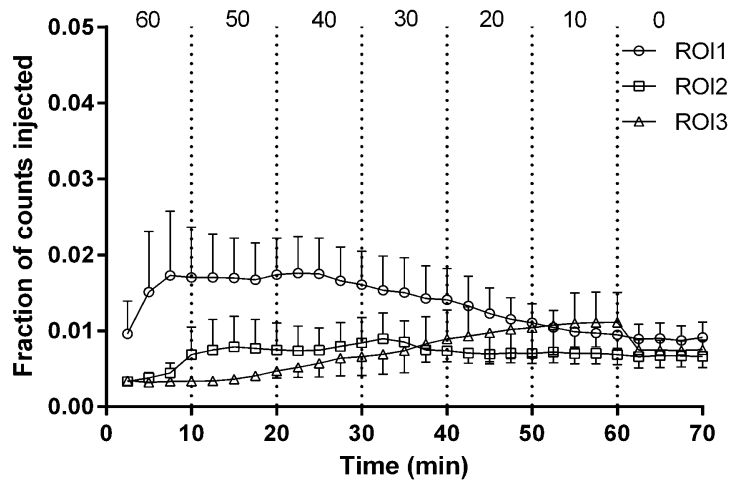

D Non-BCRL patients

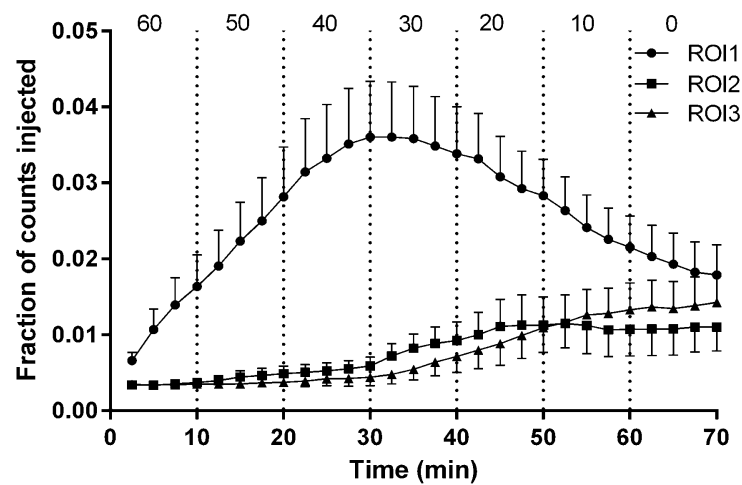

Figure 4. Radioactive counts recorded from three regions of interest (ROI) in the ipsilateral upper limb during lymphatic congestion lymphoscintigraphy and plotted as a fraction of the injected activity (means \pm SEM) against time since injection. ROI1, forearm; ROI2, subcuff; ROI3, axilla. The cuff pressure ( $\left.P_{\text {cuff }}\right)$ in $\mathrm{mmHg}$ is shown above each time interval. (A) Pre-breast cancer-related lymphedema (pre-BCRL)

patients before surgery. (B) Non-BCRL patients before surgery. (C) Pre-BCRL patients 21 weeks after surgery. (D) Non-BCRL patients 21 weeks after surgery. Before surgery (frame A versus B), the pre-BCRL fractional counts in ROI1 rose faster than non-BCRL counts over 2.5-10 min (greater $d A / d t_{\text {ROI1, }}$, see text) and reached a higher peak. Also, after $P_{\text {cuff }}$ was lowered below $P_{\text {pump }}$ the pre-BCRL counts in ROI3 rose faster than non-BCRL counts (greater $d A / d t_{\mathrm{RO} 3}$ ). At 21 weeks after surgery, transport dynamics in the pre-BCRL patients were substantially reduced compared with prior to surgery (frame A versus C), 
whereas transport dynamics in the non-BCRL patients were not reduced after surgery (frame B versus D). BCRL, breast cancer-related lymphedema; ROI, region of interest.
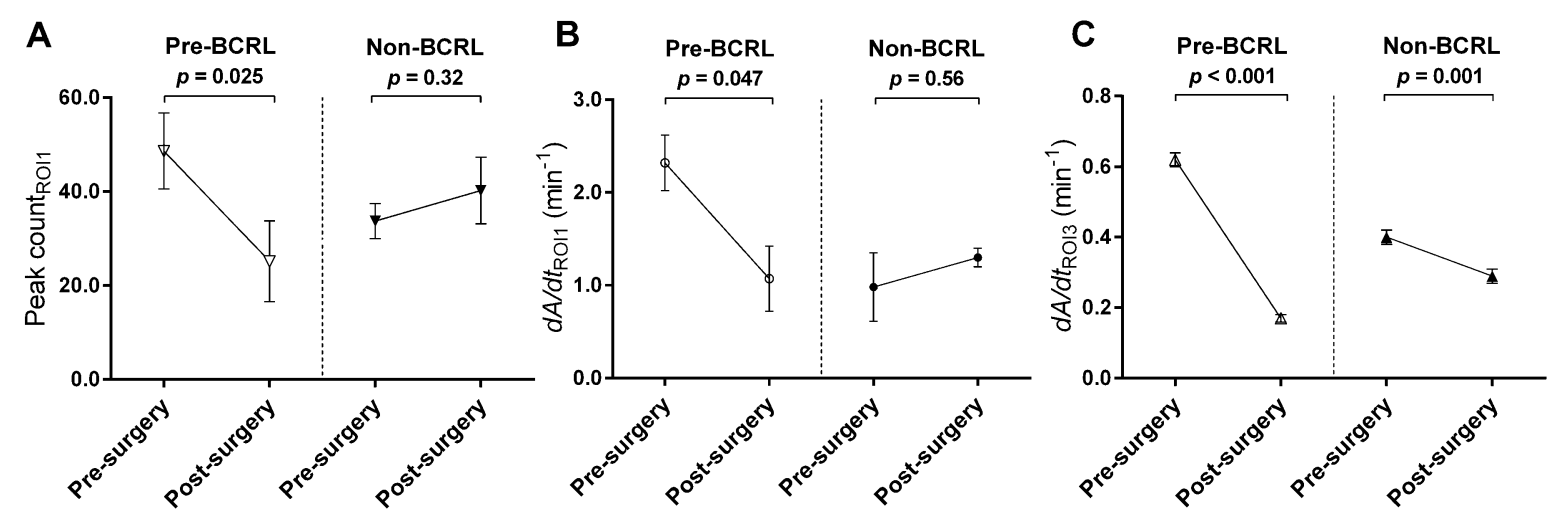

Figure 5. The effect of surgery on ${ }^{99 m}$ Tc-Nanocoll accumulation in the ipsilateral upper limb at 21 weeks after surgery in pre-BCRL and non-BCRL patients. Means $\pm S E M$, all values $\times 10^{3}$. (A) Maximum count in region of interest (ROI)1 (forearm; $n=9$ pairs for pre-BCRL, 11 pairs for non-BCRL). (B) Rate of rise of activity ( $d A / d t$ ) in ROI1. (C) Rate of rise of activity in ROI3 (axilla). $d A / d t$ was quantified by linear regression analysis of plots of mean fractional counts versus time; $d A / d t_{R O 11}$ describes transport rate from depot into forearm during the initial trapped lymph phase $(2.5-10.0 \mathrm{~min}) ; d A / d t_{\mathrm{RO} 3}$ describes transport rate beyond the cuff over 20 min after cuff pressure was reduced below lymphatic pump pressure. $p$, comparisons of presurgery with postsurgery (A, paired $t$-test; $B$ and $C$, comparison of regression slopes). Surgery greatly reduced arm lymphatic transport in the pre-BCRL group, with less effect in the non-BCRL group. BCRL, breast cancer-related lymphedema; ROI, region of interest. 